\title{
Feasibility of smartphone use in monitoring pain and symptoms among patients with serious illness
}

\author{
Korijna G. Valenti, Jaclyn Portanova, Jeffrey Laguna, Shinyi Wu, Kathleen Ell, Susan Stone, Susan Enguidanos \\ University of Southern California, United States
}

Received: April 3, 2016

Accepted: April 24, 2016

Online Published: May 5, 2016

DOI: $10.5430 /$ cns.v4n3p18

URL: http://dx.doi.org/10.5430/cns.v4n3p18

\begin{abstract}
Background: Little is known about the feasibility and acceptability of using mobile technology among seriously ill older adults experiencing moderate to severe pain.

Objective: A smartphone application was tested for feasibility and acceptability of use among ethnically-diverse older adults experiencing moderate to severe pain. Additionally, authors aimed to document patient perceived barriers and facilitators of using the mobile device for pain monitoring.

Methods: Twenty-three participants were enrolled in a prospective feasibility study and followed for 75 days. Participants were provided prepaid smartphones with a preloaded pain application and were asked to send daily reports of pain to a palliative care physician within a managed care clinic. Pain was measured on an 11-point numeric rating scale (NRS) from no pain to worst ever; patients reporting a pain scale of greater than 3 were contacted by a palliative care physician. Surveys on technology ease of use, usefulness, and intrusiveness were conducted at 30 days; qualitative interviews were conducted at the end of the 75-day study period.

Results: The study was completed fully by $74 \%$ of the sample. Qualitative analyses revealed several themes related to benefits of smartphone use in monitoring pain and symptoms While participants reported the physical challenges using the mobile application, most reported application useful, and $100 \%$ would recommend to others.

Conclusions: Older adults experiencing significant pain may be receptive to using mobile technology to monitor pain and transmit pain reports to physicians. However, simplified technological interactions are needed to overcome challenges experienced by older adults.
\end{abstract}

Key Words: Smartphone, Mobile phone, Pain, Remote monitoring, Seriously ill, Symptom management

\section{INTRODUCTION}

The prevalence of pain among seriously ill patients is high, with $26 \%$ of older adults experiencing pain in the last two years of life, ${ }^{[1]}$ and pain is the most commonly reported symptom among seriously ill patients; ${ }^{[2,3]}$ yet it often goes unrecognized and untreated. ${ }^{[4]}$ Moreover, pain has been positively associated with poorer quality of life ${ }^{[5-7]}$ depression, ${ }^{[8,9]}$ and greater caregiver burden. ${ }^{[10,11]}$ Patient self-reporting has shown to be the best way to determine the depth and breadth of pain; ${ }^{[12]}$ however, homebound patients not in immediate or constant contact with doctors and other healthcare staff often feel at a disadvantage in relation to communicating issues concerning pain. In addition, self-efficacy has been shown to improve pain management in chronic illness. ${ }^{[13]}$

A growing body of evidence supports the use of technology in monitoring pain and symptoms among individuals with

*Correspondence: Korijna G. Valenti; Email: korijna@yahoo.com; Address: University of Southern California, United States. 
complex illness. Computer use to assess symptom severity has been shown to be effective and acceptable among advanced cancer patients ${ }^{[14]}$ and tablets have been used to gather symptom information among cancer patients within a clinical setting. ${ }^{[15]}$ While evidence builds on the use of technology to monitor and assess patients with serious illness, less is known about the ability to use mobile devices. Both cellphones and smartphones have experienced an exponential growth in use across the U.S, with a 2011 survey finding that $82 \%$ of older adults have this mobile technology. ${ }^{[16]}$ While only $10 \%$ are currently using their mobile device to track their health, $42 \%$ indicated interest in doing so. ${ }^{[17]}$ With the increase in smartphone ownership, older adults have increasingly better access to technology with operating systems that might allow them to utilize applications cell phones do not offer.

However, little is known about the feasibility of using these mobile devices and applications to assess and monitor pain and symptoms among community-dwelling older patients experiencing pain.

The purpose of this study was to gather preliminary data testing the feasibility of using an electronic remote patient monitoring system for seriously ill patients experiencing pain. Additionally, the aim was to determine if these patients could use a smartphone in their home to transmit regular pain records to their physician. The research questions being investigated were: (1) Can patients experiencing pain routinely complete and submit pain assessments using a smartphone application? and (2) What are the barriers and facilitators to use of a smartphone application to assess pain among seriously ill patients?

\section{Methods}

A feasibility study was conducted to determine if a smartphone can be used to monitor pain and symptoms of seriously ill older adults. A mixed methods approach was used and included pain application reports, semi-structured surveys, and follow-up interviews to collect primary data in this feasibility study. The research university's Institutional Review Board approval was obtained from the research university conducting the study.

\subsection{Settings \& participants}

Patients were recruited from a high-risk clinic serving seriously ill patients in a managed care organization. Those 55 years and older, cognitively intact English-speaking, diagnosed with cancer, congestive heart failure, chronic obstructive pulmonary disease, or diabetes, and reporting pain severity greater than three, determined as "moderate" discomfort generally interfering with activities or relaxation, ${ }^{[19]}$

Published by Sciedu Press on an 11-point numeric rating scale (NRS) were eligible to participate in the study. Patients living in a nursing facility or assisted living and those under the care of hospice were excluded from the study.

Patients were initially identified using electronic medical records. Those meeting age and diagnosis inclusion criteria were contacted via telephone by a research assistant and screened for study eligibility and interest. An in-person meeting was scheduled at the primary care office or the patient's home for study consent and instruction on the mobile device.

\subsection{Mobile pain application}

Each participant was provided a smartphone and unlimited pre-paid service, loaded with a free, pre-existing pain and symptom application. This application used the American Pain Foundation's LOCATES ${ }^{[21]}$ methodology to collect and record data on the: (1) location of the pain, (2) other associated symptoms, (3) character of the pain, (4) aggravating and alleviating factors, (5) time and duration of pain, (6) environment where the pain occurs, and (7) pain severity. The pain application provided summary statistics of the pain reported along with charts and graphs describing the pain over time. Additionally, all phones were preloaded with text-enlarging software, contact information for study tech support, and an e-mail account.

Participants were instructed to complete the mobile pain reports daily for 75 days and transmit reports using preinstalled e-mail accounts. The application was considered as feasible if $60 \%$ of the population completed the study at 75 days, with "completion" being defined as transmitting pain reports for at least 70 days. Reports were assessed by study personnel, and reports with a pain score of four or higher were transmitted to a palliative care physician who reviewed the report and triaged it to the most appropriate resource (e.g., primary care physician, pain clinic, palliative care service) for immediate response.

\subsection{Training}

Research assistants trained patients on the smartphone and the pain application in their homes or at the primary care clinic. Participants were encouraged to bring family members and caregivers and both were trained and provided with a large-print instruction manual on the basic features of the smartphone and the mobile application. A dedicated telephone line was available to participants for additional technical support. In addition, participants failing to complete and transmit a pain report within three days of their previous report were contacted and provided additional training as needed. 


\subsection{Data collection \& measures}

\subsubsection{Demographics}

Participant demographic data were collected and included age, gender, ethnicity, marital status, living and caregiver situation, healthcare service use, and smartphone experience.

\subsubsection{Pain \& symptoms}

Pain and symptoms were collected from electronic reports submitted by participants through the mobile application.

\subsubsection{Feasibility and acceptability surveys}

Participants were contacted at 30 days following study enrollment and were surveyed on the: (1) ease of use, (2) usefulness, and (3) intrusiveness of the pain application. At the end of the study, research assistants conducted a semistructured, qualitative interview with participants to identify challenges and benefits to using the application. Participants also were asked for recommendations for improvement. All qualitative interviews were audio-recorded and transcribed.

\subsection{Data analysis}

Descriptive analysis was conducted on all project data. Openended comments and responses were examined individually and jointly by two researchers. Each researcher individually coded the transcripts and codes were compared and reconciled to $100 \%$ agreement. Codes were then reviewed to generate themes. All analysis was conducted using SPSS 21.0. ${ }^{[22]}$

\section{ResUltS}

\subsection{Sample}

About 264 patients were screened, and 43 (16.3\%) were eligible to take part in the study. Reasons for ineligibility included 221 patients (58.4\%) unable to read or speak English, $55(25.0 \%)$ with a pain score $<3,22(10.1 \%)$ with cognitive impairment, and 12 patients $(5.4 \%)$ who did not meet other study criteria. Among those eligible, 20 (46\%) did not consent to participate; 10 (50\%) cited no time/interest, 6 (30\%) cited barriers to mobile phone use, and 4 (20\%) stated excessive pain or illness precluded participation, leaving 23 (53.5\%) who consented and enrolled in the study (see Figure 1).

The sample consisted of $13(57.1 \%)$ men and $10(43.5 \%)$ women. Of this population, 14 (60.9\%) identified as Black, 6 $(26.1 \%)$ as White, $3(13 \%)$ as Hispanic/Latino; and $3(13 \%)$ identified with more than one ethnic group. The average age was 74 years $(S D=11.9)$. Nine patients $(38.1 \%)$ lived alone and $16(69.6 \%)$ held at least a high school diploma. Hypertension was the most prominent medical condition for 18 patients $(81 \%)$, with 8 patients reporting $(38.1 \%)$ heart disease, and $8(33.3 \%)$ reporting diabetes as the most common medical conditions. The average pain score at enrollment was $7.5(S D=2.0)$ with two-thirds or $15(66.7 \%)$ participants reporting a pain score of 7 or higher (see Table 1).

Table 1. Sample characteristics $(n=23)$

\begin{tabular}{|c|c|}
\hline Characteristics & N (\%) \\
\hline Age [mean $(S D)]$ & $73.96(11.90)$ \\
\hline \multicolumn{2}{|l|}{ Gender } \\
\hline - Female & $10(43.5)$ \\
\hline \multicolumn{2}{|l|}{ Race $^{*}$} \\
\hline - Black & $14(60.9)$ \\
\hline - White & $6(26.1)$ \\
\hline - Hispanic/Latino & $3(13.0)$ \\
\hline - Other Race & $3(13.0)$ \\
\hline \multicolumn{2}{|l|}{ Current marital status } \\
\hline - Married & $5(21.7)$ \\
\hline - Single & $2(8.7)$ \\
\hline - Divorced & $8(34.8)$ \\
\hline - Widowed & $8(34.8)$ \\
\hline \multicolumn{2}{|l|}{ Living Situation* } \\
\hline - Alone & $9(39.1)$ \\
\hline - With Spouse & $5(21.7)$ \\
\hline - With Child & $6(26.1)$ \\
\hline - With Paid Caregiver & $0(0)$ \\
\hline - Other Individual & $4(17.4)$ \\
\hline Initial Pain (NPIS 1-10) [mean (SD)] & $7.48(2.02)$ \\
\hline \multicolumn{2}{|l|}{ Medical Condition* } \\
\hline - Cancer & $4(17.4)$ \\
\hline - Heart Disease & $8(34.8)$ \\
\hline - COPD & $5(21.7)$ \\
\hline - Hypertension & $18(78.3)$ \\
\hline - Diabetes & $8(34.8)$ \\
\hline - Other Diagnosis & $14(60.9)$ \\
\hline \multicolumn{2}{|l|}{ Primary Language } \\
\hline - English & $19(82.6)$ \\
\hline - Spanish & $2(8.7)$ \\
\hline - Missing & $2(8.7)$ \\
\hline \multicolumn{2}{|l|}{ Who helps you care for yourself* } \\
\hline - No one & $6(26.1)$ \\
\hline - Spouse & $2(8.7)$ \\
\hline - Children/grandchildren & $5(21.7)$ \\
\hline - Other/multiple & $10(43.4)$ \\
\hline Currently Retired & $20(87.0)$ \\
\hline \multicolumn{2}{|l|}{ Education } \\
\hline - Less than high school & $6(26.1)$ \\
\hline - High School/ GED/ Some college & $14(60.9)$ \\
\hline - College grad or postgrad & $2(8.7)$ \\
\hline - Missing & $1(4.3)$ \\
\hline Emergency Department Visit in past six months & $12(52.2)$ \\
\hline - Number of visits [mean $(S D)]$ & $3.52(7.0)$ \\
\hline Hospitalized in the past six months & $11(47.8)$ \\
\hline - Number of visits [mean $(S D)]$ & $1.17(2.1)$ \\
\hline
\end{tabular}

"Total percentage may exceed 100\%

\subsection{Pain application use}

Among participants, 6 patients (26\%) discontinued the use of the pain assessment tool. One patient lost the phone, 1 cited administrative withdraw due to language barriers (spoke En- 
glish but could not read), 1 patient died, and 3 had difficulties using the device (see Figure 1).

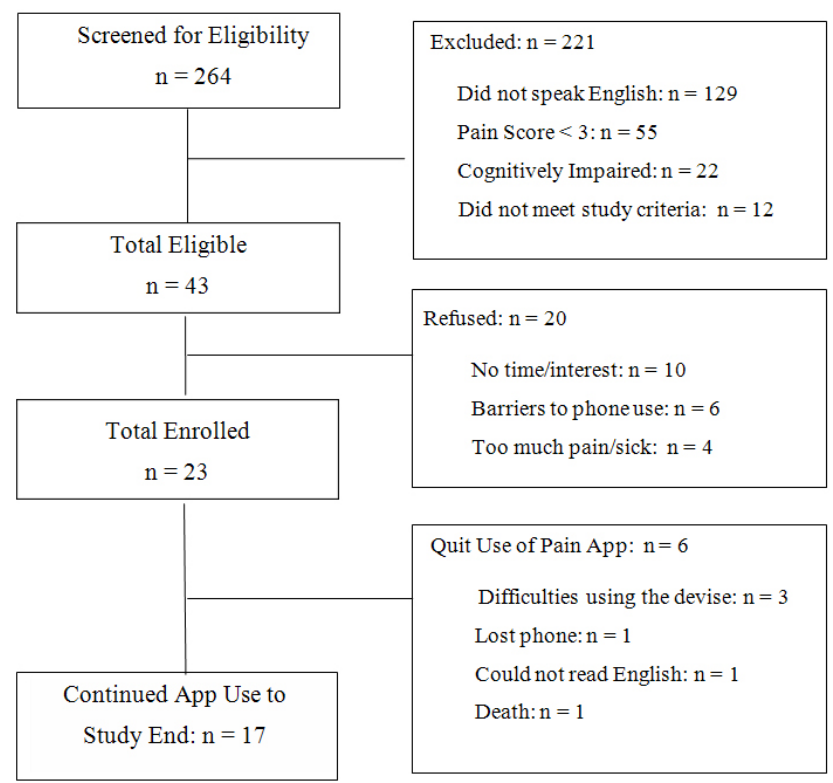

Figure 1. Study enrollment and application completion

\subsection{Training time}

All participants received initial training on the smartphone that lasted, on average, 75 minutes, and ranged from 15 to 120 minutes (median 60 minutes; $S D=0.47$ ). Number of follow-up contacts to prompt participants to complete and send assessments ranged from 0 to 14, with an average of $2.77(S D=3.9)$ contacts per participant. $14(36.6 \%)$ contacts were via phone, $2(9.8 \%)$ were trained in person at the clinic, and $10(53.7 \%)$ were trained at home. Total training time for participants ranged from 1 to 15 hours, with $19(81 \%)$ participants receiving no more than four hours (see Table 2).

\subsection{Qualitative analysis and emerging themes \\ 3.4.1 Patient identified facilitators and barriers to mobile pain reporting}

In analyzing qualitative data obtained during interviews, three major themes emerged including: (1) ease of use, (2) improved connectedness, and (3) positive attitudes toward the pain application (see Table 3). In terms of ease of use, a primary barrier to the use of the pain application was the lack of familiarity with the smartphone. Although $60 \%$ of participants previously used a cell phone, only one had experience using a smartphone. Having family members to help with the application facilitated use for half of the participants; $10(47.6 \%)$ respondents cited that children or grandchildren helped them complete and send reports. Patients also identified physical barriers in the use of the smartphone including lack of sensitivity to the touchscreen and poor vision. Many participants voiced the need for a larger device with larger buttons to facilitate use while others felt a voice recognition and activation system would improve the current system. Comments about these limitations included "Hard to get fingers working on the phone"; "Touch screen is difficult, simplify it! Need a bigger device to record pain"; "Would like for the app to be more detailed"; and "Letters on the touch pad was difficult- participant was frustrated".

Table 2. Technology experience, assistance and training time

\begin{tabular}{ll}
\hline Characteristics & N (\%) \\
\hline Technology (n = 22) & \\
- Previously used a cell phone & $14(63.6)$ \\
- Previously used a smartphone & $1(4.6)$ \\
Who helped with app? $(\mathrm{n}=21)$ & \\
- No one & $5(23.8)$ \\
- Friend & $2(9.5)$ \\
- Children/grandchildren & $10(47.6)$ \\
- Other & $4(19.1)$ \\
Training Time [mean $(S D)]$ & \\
- Total hours spent training & 68.5 \\
- Initial training time & $1.25(.47)$ \\
- Number of follow up visits & $2.77(3.93)$ \\
- Average training time per subject & 2.98 \\
- Follow up visit time & $1.81(2.20)$ \\
\hline
\end{tabular}

Table 3. Themes on challenges and benefits to pain application use
1. Ease of Use
- Difficulty with small size of device, keypad, etc.
- Need for help from family members.
2. Improved Connectedness
- Enhanced participant understanding of their condition/pain.
- Greater confidence in the medical team's knowledge of condition/pain.
3. Positive Attitude Toward Pain Application

The second theme, improved connectedness, related to improved connections to the physician as well as their own pain experiences. Several patients reported that receipt of immediate response from the physician was a motivator for participation. Patients also reported interest in recording pain and symptoms for their own peace of mind. The ability to use this technology from home was viewed as a benefit to the patients. As stated by one patient, "It's really nice to do it from home." Others talked about how it "helped me to express my pain".

Positive attitudes toward the pain application were expressed through statements such as "It is a beautiful thing"; "It will be the way of the future" and "I love it to death". 


\subsubsection{Ease, usefulness and intrusiveness}

Overall, participants had a positive view of the application, with few remarking that the application was a bother or a concern for privacy. About $30 \%$ reported difficulty pushing buttons and about half (48\%) agreed it would be easier to give answers to a real person. About three-quarters agreed that the application was easy to understand, use, and remember to use, enjoyable, and facilitated connectedness with health care providers. All (100\%) stated they would recommend the application to a friend with similar health conditions (see Table 4).

Table 4. Ease of use, usefulness, and intrusiveness of mobile pain application use $(n=21)$

\begin{tabular}{|c|c|}
\hline Question & Agree \\
\hline \multicolumn{2}{|l|}{ Ease of Use } \\
\hline - Touch screen hard to see & $14 \%$ \\
\hline - Difficulty pressing buttons & $30 \%$ \\
\hline - Would prefer automated calls & $43 \%$ \\
\hline - Giving answers to a real person easier than app & $48 \%$ \\
\hline - Touch screen easy to use & $52 \%$ \\
\hline - Alarm reminded patient to complete app & $62 \%$ \\
\hline - Easy to remember to use app everyday & $67 \%$ \\
\hline - Easy to remember to use everyday & $76 \%$ \\
\hline - Language easy to understand & $76 \%$ \\
\hline - Pain app easy to use & $76 \%$ \\
\hline - Length of app survey seems right & $85 \%$ \\
\hline - Easy to read screen & $86 \%$ \\
\hline - Easy to understand questions & $95 \%$ \\
\hline - Would recommend this type of app to a friend & $100 \%$ \\
\hline \multicolumn{2}{|l|}{ Usefulness } \\
\hline - App could alert patient to new health problem & $57 \%$ \\
\hline - App helped patient manage your health & $62 \%$ \\
\hline - Just as effective as in person visit & $62 \%$ \\
\hline - App could alert RN/MD to new health problem & $67 \%$ \\
\hline - Responses helped patient understand pain & $68 \%$ \\
\hline - Wouldn't mind using app as part of care in the future & $68 \%$ \\
\hline - Training helped patient understand app & $71 \%$ \\
\hline \multicolumn{2}{|l|}{ Intrusiveness } \\
\hline - Worried about privacy & $5 \%$ \\
\hline - It was a bother & $10 \%$ \\
\hline - Using app interferes with lifestyle & $15 \%$ \\
\hline - It takes too much time & $19 \%$ \\
\hline - Couldn't give honest answers because of privacy concerns & $19 \%$ \\
\hline - App made patient feel like RN/MD accessible & $71 \%$ \\
\hline - Enjoyed using the pain app & $71 \%$ \\
\hline - App made patient confident RN/MD knew how you were doing & $71 \%$ \\
\hline - Knowing RN/MD monitoring gives patient peace of mind & $76 \%$ \\
\hline
\end{tabular}

\section{Discussion}

This feasibility study aimed to determine if smartphone technology could be used by seriously ill patients to monitor their pain and symptoms. Although just over half of eligible patients agreed to participate, this number may increase with a simplified technological interface; about one-third refused to participate due to the complicated nature of the technology. Participants identified mechanisms to improve ease of use including voice activated systems, and larger screens and buttons. Despite these barriers, participants reported high levels of acceptability of the mobile phones and high levels of interest. Notably, all participants stated they would recommend this device to a friend experiencing similar health problems.

Ease in the use of the device and application was a challenge in this study. In a study conducted using a personal digital assistant (PDA) to record pain and symptoms among cancer patients ${ }^{[17]}$ researchers found that participants initially had concerns about the mobile phone use, with most comfortable by the end of the 30-day study. The complicated nature of the pre-existing application in this study was unable to achieve similar growth in comfort and ease of use.

Compared with other studies, this sample may have been older and experiencing higher levels of pain. In a study assessing the feasibility of using computers to measure pain and symptoms, researchers found that non-completers were more likely to be older participants and those experiencing more pain. ${ }^{[14]}$ In a study conducted in England using an application programmed into a mobile phone, average age of participants was 62 (as compared to this study's average of 74), and although pain and symptoms were targeted, having a specified pain level was not a study criterion. ${ }^{[17]}$

The finding of family support in completing the pain application is supported by the PDA study conducted in England. ${ }^{[16]}$ Nearly half of participants had family aid in completing and sending pain reports. The PDA study reported that about $25 \%$ of their participants had help from family members. Their level of help may be lower due to the lower age of the participants and the simplicity of the program they used.

This study demonstrates the ability to engage seriously ill patients experiencing moderate to severe pain in the use of mobile phone to monitor pain and symptoms. Two-thirds of those participating reported severe pain (pain $>7$ ) at the time of enrollment, yet despite these high levels of pain and no familiarity with smartphone technology, they were willing to participate in the study. One motivating factor may be the potential for ready access to medical care and healthcare professionals. The majority agreed that the application gave them peace of mind and greater confidence in the medical team's knowledge of their condition. This finding is similar to others that found that cancer patients participating in telehealth interventions felt increased comfort and safety from use of an electronic system. ${ }^{[16,18]}$ 


\subsection{Limitations}

This was a small feasibility study conducted within one geographic location and may not be representative of other populations. Additionally, participants had a wide range of illnesses that may have influenced enrollment decisions.

Information gathered here can inform future studies using smartphone technology with older adults. Use of smartphones to monitor pain and symptoms is acceptable to diverse older adults but may require extensive training and coaching. Most barriers to use were physical barriers and barriers related to the complicated nature of the program, pointing to the need to have less complicated systems with options for touchscreen response (such as voice recognition). Further research is needed to determine if simplified technologies increase enrollment in such programs and sustained participation.

\subsection{Implications for nurses}

Nurses play a significant role in patient pain education, selfmanagement, and communication with other providers. The
Nursing Process consisting of assessment, diagnosis, planning, implementation and evaluation can be enhanced with the use of new technologies that provide longitudinal and timely patient pain data. Further, nurses are well-positioned to identify patient needs and abilities and provide recommendations to providers on which patients could benefit from a pain monitoring device.

\section{Conclusions}

From the positive response received from the majority of the patients, and despite the issues found with the application and technology, implications for future applications for pain and symptom monitoring are significant. Clearly, a simpler user interface is needed to facilitate use as well as improved access to a live medical professional to respond to patients' pain and related concerns. An application designed to address these barriers may provide a viable addition to current pain management strategies.

\section{CONFlicts of InTEREST Disclosure}

The authors declare they have no conflict of interest.

\section{REFERENCES}

[1] Smith AK, Cenzer IS, Knight SJ, et al. The Epidemiology of Pain During the Last 2 Years of Life. Annals of Internal Medicine. 2010; 153(9): 563. PMid: 21041575. http://dx.doi.org/10.7326/0 003-4819-153-9-201011020-00005

[2] Tranmer JE, Heyland D, Dudgeon D, et al. Measuring the symptom experience of seriously ill cancer and noncancer hospitalized patients near the end of life with the memorial symptom assessment scale. J Pain Symptom Manage. 2003; 25(5): 420-429. http://dx.doi.org/10.1016/S0885-3924(03) 00074-5

[3] Desbiens NA, Mueller-Rizner N, Connors AF, et al. The symptom burden of seriously ill hospitalized patients. J Pain Symptom Manage. 1999; 17(4): 248-255. http://dx.doi.org/10.1016/S0885-3 924 (98) 00149-3

[4] Wilkie DJ, Ezenwa MO. Pain and symptom management in palliative care and at end of life. Nurs Outlook. 2012; 60(6): 357-364. PMid: 22985972. http://dx.doi.org/10.1016/j.outlook.2 012.08 .002

[5] Mularski R, Puntillo K, Varkey B, et al. Pain management within the palliative and end-of-life care experience in the ICU. Chest. 2009; 135: 1360-1369. PMid: 19420206. http://dx.doi.org/10.13 78/chest. 08-2328

[6] Teno JM, Clarridge BR, Casey V, et al. Family perspectives on endof-life care at the last place of care. JAMA. 2004; 291: 88-93. PMid: 14709580. http://dx.doi.org/10.1001/jama.291.1.88

[7] Reyes-Gibby CC, Aday L, Cleeland C. Impact of pain on self-rated health in the community- dwelling older adults. Pain. 2002; 95(12): 75-82. http://dx.doi .org/10.1016/S0304-3959(01) 003 $75-\mathrm{X}$

[8] Aukst-Margetic B, Jakovljevic M, Margetic B, et al. Religiosity, depression and pain in patients with breast cancer. Gen Hosp Psychiatry.
2005; 27(4): 250-255. PMid: 15993256. http://dx.doi .org/10. 1016/j .genhosppsych. 2005.04.004

[9] Zimmerman L, Story KT, Gaston-Johansson F, et al. Psychological variables and cancer pain. Cancer Nurs. 1996; 19(1): 44-53. PMid: 8904386. http://dx.doi.org/10.1097/00002820-199 602000-00006

[10] Tilden VP, Tolle SW, Drach LL, et al. Out-of-hospital death: advance care planning, decedent symptoms, and caregiver burden. JAGS 2004; 52(4): 532-9. PMid: 15066067. http://dx.doi.org/10. $1111 / j .1532-5415.2004 .52158 . x$

[11] Miaskowski C, Kragness L, Dibble S, et al. Differences in mood states, health status, and caregiver strain between family caregivers of oncology outpatients with and without cancer-related pain. J Pain Symptom Manage. 1997; 13(3): 138-47. http://dx.doi.org/10. 1016/S0885-3924 (96) 00297-7

[12] Skrobik Y, Chanques G. The pain, agitation, and delirium practice guidelines for adult critically ill patients: a post-publication perspective. Annals of Intensive Care 3.1. 2013; 3(1): 1-9.

[13] Porter L, Keefe F, Garst J, et al. Self-efficacy for managing pain symptoms, and function in patients with lung cancer and their informal caregivers: Association ns with symptoms and distress. Pain. 2007; 137: 306-315. PMid: 17942229. http://dx.doi.org/10. $1016 / j \cdot$ pain $\cdot 2007.09 .010$

[14] Hjermstad MJ, Lie HC, Caraceni A, et al. Computer-based symptom assessment is well- accepted by patients with advanced cancer. Palliat Med. 2012; 26(4): 443-444.

[15] Abernathy AP, Herndon JE, Wheeler JL, et al. Improving health care efficiency and quality using tablet personal computers to collect research-quality, patient reported data. Health Serv Res. 2008; 43(6): 1975-1991. PMid: 18761678. http://dx.doi.org/10.1111/j $.1475-6773.2008 .00887 . x$ 
[16] Barrett LL. Health and caregiving among the 50+: Ownership, use, and interest in mobile technology. 2011. Available from: http://assets.aarp.org/rgcenter/general/healt h-caregiving-mobile-technology.pdf

[17] McCall K, Keen J, Farrer K, et al. Perceptions of the use of a remote monitoring system in patients receiving palliative care at home. Int J Palliat Nurs. 2008; 14(9): 426-31. PMid: 19060793. http://dx.doi.org/10.12968/ijpn.2008.14.9.31121

[18] Stern A, Valaitis R, Weir R, et al. Use of home telehealth in palliative cancer care: a case study. J Telemed Telecare. 2012; 18(5): 297-300 PMid: 22790013. http://dx.doi.org/10.1258/jtt.2012.11 1201
[19] 0 - 10 Pain Scale. Lucile Packard Children's Hospital Heart Center/CVICU.

[20] Hjermstad MJ, Fayers PM, Dagny FH, et al. Studies comparing numerical rating scales, verbal rating scales, and visual analogue scales for assessment of pain intensity in adults: A systematic literature review. J Pain Symptom Manage. 2011; 41(6): 1073-1093. PMid: 21621130 . http://dx.doi.org/10.1016/j.jpainsymm an.2010.08.016

[21] Harutyunyan R. Talking to your doctor about chronic pain. 2008. Available from: www . emaxhealth.com/2/82/24723.html

[22] IBM Corp. Released 2012. IBM SPSS Statistics for Windows, Version 21.0. Armonk, NY: IBM Corp. 